\title{
HLA antigens and other risk factors in the development of retinopathy in type 1 diabetes
}

\author{
R. S. GRAY, I. R. STARKEY,' S. RAINBOW, ${ }^{3}$ A. B. KURTZ, ${ }^{4}$ \\ A. ABDEL-KHALIK,${ }^{2}$ S. URBANIAK ${ }^{2}$ R. A. ELTON,${ }^{5}$ L. J. P. DUNCAN, ${ }^{1}$ AND \\ B. F. CLARKE' \\ From the ${ }^{1}$ Diabetic and Dietetic Department and ${ }^{2}$ Blood Transfusion Unit, Royal Infirmary, \\ Edinburgh; ${ }^{3}$ Department of Medical Biochemistry, University Hospital of Wales, Heath Park, Cardiff; \\ ${ }^{4}$ Institute of Nuclear Medicine, Middlesex Hospital Medical School, London W1; and the \\ ${ }^{5}$ Medical Statistics and Computing Unit, University of Edinburgh
}

SUMMARY Factors possibly influencing the development of diabetic retinopathy were studied in 112 randomly selected type 1 diabetics having no or minimal retinopathy (group A) and in 82 type 1 diabetics with known severe diabetic retinopathy. The latter comprised those with severe background retinopathy (group $\mathrm{B}, \mathrm{n}=17$ ) and those having proliferative retinopathy without (group C, $\mathrm{n}=38$ ) and with (group $\mathrm{D}, \mathrm{n}=27$ ) diabetic nephropathy. Nonretinopaths (group A) were of similar sex ratio, body weight, and age at diagnosis of diabetes but had been diabetic longer $(p<0.001)$ and were thus older $(p<0 \cdot 001)$ than retinopaths (groups B-D). The distribution of HLA antigens of the $A, B$, and $C$ loci was similar in nonretinopaths and retinopaths with the exception that HLA B7 showed a reduced $(p<0.05)$ prevalence in the retinopaths $(6 \%$ versus $17 \%)$ and was singularly underrepresented in group $\mathrm{D}$, where no patients had this antigen. Mean postprandial plasma glucose and $\mathrm{HbA}_{1}$ concentrations were higher $(\mathrm{p}<0.01$ and $\mathrm{p}<0.001)$ and cigarette smoking was more prevalent $(p<0 \cdot 01)$ in the retinopathy groups B-D than in group A. Systolic and diastolic blood pressures were similar in groups A-C, with higher $(p<0 \cdot 001)$ values only in group $D$. There was no association between insulin antibody binding in the serum or measurable plasma $C$-peptide immunoreactivity and retinopathy status. The risk of development of diabetic retinopathy in type 1 diabetes may be related to HLA-associated genetic factors and to cigarette smoking.

In order to evaluate the possible factors which may influence the incidence, severity and progress of retinopathy in type 1 diabetics we have examined the frequencies of the HLA antigens of the A, B, and C loci, selecting only those diabetics who had either developed severe diabetic retinopathy or exhibited an apparent immunity to the development of other than very mild background diabetic retinopathy. Since duration of diabetes is possibly the most important determinant of the development of diabetic retinopathy, we have taken particular care to select retinopaths of short duration of diabetes and nonretinopaths of long duration of diabetes. In addition to considering HLA antigen frequencies we have compared the 2 groups of diabetics in respect of Correspondence to $\operatorname{Dr}$ R. S. Gray, Diabetic and Dietetic Department, Royal Infirmary, Edinburgh EH3 9YW. postprandial plasma glucose concentration, total glycosylated haemoglobin $\left(\mathrm{HbA}_{1}\right)$, insulin antibody binding by serum, prevalence of diastolic and systolic hypertension, and smoking history. Finally, we have shown that all subjects studied were type 1 diabetics by confirming an absent or only just measurable postprandial C-peptide concentration in the plasma. We thus avoided the risk of inadvertently including subjects with 'maturity onset diabetes of the young' in the group of nonretinopaths.

\section{Patients and methods}

PATIENTS

All 194 diabetics studied attended the Diabetic and Dietetic Department, Royal Infirmary, Edinburgh, having presented with clinical features of type 1 
diabetes before the age of 35 years and having been treated with insulin from the outset.

Nonretinopaths. One hundred and twelve unrelated diabetics (49 males, 63 females) were randomly selected from a cohort of patients who are the subject of a long-term prospective study of the development of retinopathy. All such patients were known to have been diabetic for at least 15 years, in which time they had no ophthalmoscopic evidence of diabetic retinopathy.

Retinopaths. Seventy-three unrelated diabetics (44 males, 29 females) with severe background or proliferative retinopathy were studied representing all available type 1 diabetics of duration of diabetes less than 25 years who had been referred to the Princess Alexandra Eye Pavilion, Edinburgh, during 1972-8 for treatment of diabetic retinopathy, from the Diabetic and Dietetic Department, Roval Infirmary, Edinburgh. In order to correct for the male preponderance found in this group of patients a further 9 female retinopaths were included whose proliferative retinopathy was diagnosed in 1979-80.

Nondiabetic controls. One hundred blood donors (50 males, 50 females) were HLA typed.

\section{METHODS}

All diabetics' fundi were examined ophthalmoscopically through dilated pupils by one observer (B.F.C.), who assessed the corrected near visual acuity (by standard reading test types) in each patient together with blood pressure in the sitting position after resting quietly for at least $5 \mathrm{~min}$. Patients receiving antihypertensive treatment whose diastolic and/or systolic pressures had previously been recorded as greater than 85 and $155 \mathrm{mmHg}$. respectively, were identified.

Past and present degrees of proteinuria were assessed by Multistix (Ames Co.).

A questionnaire regarding cigarette smoking habits and family history of diabetes was completed by each diabetic.

A single venous blood sample was withdrawn from each diabetic 1-2 hours after breakfast and was analysed in the following manner. HLA typing was carried out in $104(93 \%)$ nonretinopaths and in all retinopaths $(n=82)$ and nondiabetic controls $(n=100)$. Diabetics and controls were typed concurrently by the standard National Institutes of Health (NIH) lymphocyte cytotoxicity technique against a panel of 120 antisera defining the following locus A, B, and C specificities: HLA A 1.2,28, 3, 9 $(23,24), 10(25,26), 11,19,29,30,31,32,33$. HLA B $5,7,8,12,(44,45), 13,14,15,16,(38,39), 17,18,21$. (49, 50), 22, 27, 35, 37, 40, BW4 and BW6. HLA C CW3 CW4.

In all $(\mathrm{n}=112)$ nonretinopaths and $79(96 \%)$ retinopaths the following investigations were carried out. $\mathrm{HbA}_{1}$ was measured by a modification' ${ }^{1}$ of the column chromatographic technique of Kynoch and Lehmann. ${ }^{2}$ Reversible and stable forms of $\mathrm{HbA}_{1}$ were not separated by dialysis of red cells. ${ }^{3}$ Betweenbatch precision, estimated by repeat analysis of specimens from patients, showed a coefficient of variation $(\mathrm{CV})$ of $3.5 \%$. The normal range in nondiabetics in our laboratory is $5 \cdot 2-8 \cdot 4 \%$.

Plasma glucose was estimated by a standard glucose oxidase method. ${ }^{4}$

The binding of ${ }^{125}$ I-labelled beef insulin by serum samples was determined by a method using polyethylene glycol separation. ${ }^{5}$ The nonspecific binding did not exceed $1.5 \%$, and all samples were analysed in one assay, with precision of $2.5 \%(\mathrm{CV})$ across the range. Results are expressed as percentage of labelled insulin bound.

C-peptide was measured by radioimmunoassay by a modification of the method described by Heding. ${ }^{6}$ Antibody M1230 raised against human C-peptide was used at an initial dilution of $1 / 25000$. The detection limit of the assay was $0.04 \mathrm{nmol} / \mathrm{l}$ (calculated as 2 standard deviations (SD) from 0). Cross-reaction with human proinsulin is $11 \%$ on a molar basis. The interassay coefficient of variation was $6 \%$. Antibody M1230, human C-peptide standard, and iodinated tyrosylated C-peptide were gifts of the Novo Research Institute, Copenhagen. Denmark.

Comparison of groups was by Wilcoxon rank sum. Kruskal-Wallis, or chi-square tests as appropriate. and relationships between variables were tested by Kendall rank correlation $(\tau)$.

Results are presented as mean $\pm(\mathrm{SD})$ unless otherwise stated.

\section{Results}

Thirty-one nonretinopaths $(28 \%)$ had minimal diabetic venous changes and/or less than 5 microaneurysms in each fundus, while the remaining $81(72 \%)$ nonretinopaths had no ophthalmoscopic evidence of diabetic retinopathy. All 112 diabetics were assigned to group $\mathrm{A}$ and hereafter continue to be referred to collectively as nonretinopaths. Seventeen retinopaths (8 males, 9 females; group B) had severe background retinopathy as evidenced by widespread microaneurysms, blot, flame, or subhyaloid haemorrhages with or without hard or soft exudates but did not exhibit and had not previously exhibited new vessel formation. Sixty-five retinopaths ( 37 males, 28 females) had proliferative diabetic retinopathy and were divided into patients without ( 18 males, 20 females; group C) and with (18 males, 9 females; group D) diabetic nephropathy (vide infra). 
Table 1 Clinical characterisation of nonretinopaths and retinopaths

\begin{tabular}{|c|c|c|c|c|}
\hline & \multirow[t]{2}{*}{ Nonretinopaths } & \multicolumn{2}{|l|}{ Retinopaths } & \multirow{2}{*}{$\begin{array}{l}\text { Significance } \\
\begin{array}{l}\text { Nonretinopaths vs. } \\
\text { retinopaths }\end{array}\end{array}$} \\
\hline & & Severe background & Proliferative & \\
\hline Number of subjects & 112 & 17 & 65 & - \\
\hline Sex (\% male) & 44 & 47 & 55 & NS \\
\hline Age (years) & $46 \pm 14$ & $34 \pm 8$ & $37 \pm 11$ & $\mathrm{p}<0.001$ \\
\hline Duration of diabetes at time of study & $26 \pm 10$ & $12 \pm 4$ & $21 \pm 7$ & $\mathrm{p}<0.001$ \\
\hline \multicolumn{5}{|l|}{$\begin{array}{l}\text { Duration of diabetes at diagnosis-of } \\
\text { severe background and proliferative }\end{array}$} \\
\hline retinopathy (years) & - & $12 \pm 3$ & $18 \pm 6$ & - \\
\hline Insulin regimen: daily dose (units) & $59 \pm 23$ & $60 \pm 28$ & $64 \pm 30$ & NS \\
\hline * Receiving conventional beef insulin (\%) & 72 & 65 & 71 & NS \\
\hline Receiving once daily insulin (\%) & 56 & 47 & 52 & NS \\
\hline tIdeal body weight (\%) & $100 \pm 13$ & $103 \pm 14$ & $99 \pm 13$ & NS \\
\hline Diabetic first-degree relative (\%) & 21 & 12 & 26 & NS \\
\hline Visual acuity: better eye & $5 \cdot 4 \pm 1 \cdot 6$ & $6 \cdot 3 \pm 4 \cdot 6$ & $8 \cdot 3 \pm 10 \cdot 6$ & - \\
\hline $\begin{array}{l}\text { worse eye } \\
\text { war }\end{array}$ & $7 \cdot 2 \pm 7 \cdot 0$ & $7 \cdot 0 \pm 5 \cdot 1$ & $23 \cdot 1 \pm 20 \cdot 3$ & - \\
\hline \$Proteinuria grade 0 & 104 & $16(1)$ & $32(1)$ & \\
\hline 1 & 6 & 0 & 6 & \\
\hline 2 & 2 & 0 & $17(2)$ & \\
\hline 3 & 0 & $1(1)$ & $10(7)$ & \\
\hline
\end{tabular}

* Patients not on conventional beef insulin had been converted to highly purified pork insulin up to 3 years prior to time of study.

+Metropolitan Life Assurance Tables. 1959.

\$Proteinuria grade: $0=$ no proteinuria; $1=$ =intermittent proteinuria; $2=$ persistent proteinuria; $3=$ nephrotic syndrome-patients with raised creatinine in parenthesis.

Results are expressed as mean \pm SD.

Owing to the method of patient selection nonretinopaths had been diabetic longer $(p<0 \cdot 001)$ and were older $(p<0 \cdot 001)$ than retinopaths, but there was no significant difference in sex ratio, daily insulin dose, percentage of ideal body weight, insulin regimen, or family history of diabetes (Table 1) between nonretinopaths and retinopaths. The visual acuity in each eye of proliferative retinopaths was worse $(p<0.001$ and $<0.001)$ than that of nonretinopaths (Table 1).
The prevalence of proteinuria and renal failure (serum creatinine $>150 \mu \mathrm{mol} / \mathrm{l}$ ) in nonretinopaths and retinopaths is also shown in Table 1. Patients with persistent proteinuria or the nephrotic syndrome (without evidence of other than diabetic renal disease) are defined as having diabetic nephropathy.

HLA TYPING

Table 2 shows the distribution of HLA antigens in the subjects studied which are reported to be over- or

Table $2 H L A$ antigen frequencies (\%) in study group

\begin{tabular}{|c|c|c|c|c|c|c|c|c|c|c|c|}
\hline \multirow[t]{3}{*}{$H L A$} & \multicolumn{6}{|c|}{ Diabetic groups } & \multirow{3}{*}{$\begin{array}{l}\text { Controls } \\
100\end{array}$} & \multicolumn{4}{|c|}{ Significance } \\
\hline & $\boldsymbol{A}$ & $B$ & $C$ & $D$ & $B+C+D$ & $A+B+C+D$ & & (l) & (2) & (3) & (4) \\
\hline & $n=104$ & 17 & 38 & 27 & 82 & 186 & & & & & \\
\hline Al & 48 & 47 & 50 & 56 & 51 & 50 & 31 & NS & NS & $p<0.01$ & NS \\
\hline B7 & 17 & 12 & 8 & 0 & 6 & 12 & 26 & NS & $p<0.05$ & $p<0.01$ & $p<0.05$ \\
\hline B8 & 46 & 47 & 58 & 55 & 55 & 50 & 23 & NS & NS & $p<0.001$ & NS \\
\hline B15 & 21 & 6 & 13 & 22 & 15 & 18 & 10 & NS & NS & NS & NS \\
\hline B18 & 4 & 18 & 8 & 15 & 12 & 7 & 5 & NS & NS & NS & NS \\
\hline$A 1+B 8$ & 42 & 29 & 47 & 52 & 45 & 43 & 18 & NS & NS & $p<0.001$ & NS \\
\hline B8-A1 & 4 & 18 & 10 & 4 & 10 & 6 & 5 & NS & NS & NS & NS \\
\hline $\mathrm{B} 8+\mathrm{B} 15$ & 6 & 6 & 5 & 11 & 7 & 6 & 2 & NS & NS & NS & NS \\
\hline
\end{tabular}

Significance: (1) Among groups B, C, and D. (2) Groups B, C, and D vs. group A. (3) Groups A, B, C. and D vs. controls. (4) Group A vs. Groups C and D.

Group $A=$ nonretinopaths. Group $B=$ severe background retinopaths. Group $C=$ proliferative retinopaths without diabetic nephropathy. Group $\mathrm{D}=$ proliferative retinopaths with diabetic nephropathy. 
Table 3 Risk factors in nonretinopaths and retinopaths

\begin{tabular}{|c|c|c|c|c|c|}
\hline & \multicolumn{4}{|c|}{ Diabetic groups } & \multirow[t]{2}{*}{ Overall comparison } \\
\hline & $\boldsymbol{A}$ & $\boldsymbol{B}$ & $C$ & $D$ & \\
\hline $\begin{array}{l}\text { Number of subjects } \\
\text { HbA, }(\%) \\
\text { Postprandial plasma glucose (mmol/l) } \\
\text { Beef insulin antibody binding (\%) } \\
\text { Plasma C-peptide* (nmol/l) }\end{array}$ & $\begin{array}{l}112 \\
12 \cdot 1 \pm 1 \cdot 8 \\
12 \cdot 6 \pm 5 \cdot 8 \\
23 \cdot 2 \pm 16 \cdot 1 \\
0 \cdot 08 \pm 0 \cdot 04 \\
(0 \cdot 04-0 \cdot 29)\end{array}$ & $\begin{array}{l}17 \\
15 \cdot 0 \pm 2 \cdot 5 \\
18 \cdot 7 \pm 8 \cdot 2 \\
17 \cdot 2 \pm 13 \cdot 0 \\
0 \cdot(09 \pm 0 \cdot 04 \\
(0 \cdot 04-0 \cdot 17)\end{array}$ & $\begin{array}{l}36 \\
13 \cdot 3 \pm 2 \cdot 1 \\
14 \cdot 9 \pm 8 \cdot 2 \\
21 \cdot 7 \pm 18 \cdot 8 \\
0 \cdot 10 \pm 0 \cdot 13 \\
(0 \cdot 04-0 \cdot 47)\end{array}$ & $\begin{array}{l}25 \\
13 \cdot 6 \pm 2 \cdot 5 \\
17 \cdot 1 \pm 9 \cdot 9 \\
16 \cdot 4 \pm 12 \cdot 4 \\
0 \cdot 05 \pm 0 \cdot 06 \\
(0 \cdot 04-0 \cdot 06)\end{array}$ & $\begin{array}{l}p<0 \cdot(001 \\
p<0 \cdot 05 \\
\text { NS } \\
\text { NS }\end{array}$ \\
\hline $\begin{array}{l}\text { Diastolic hypertension (\%) } \\
\text { (>85 mmHg) } \\
\text { Systolic hypertension (\%) }\end{array}$ & 14 & 0 & 11 & 56 & $\mathrm{p}<0.001$ \\
\hline $\begin{array}{l}\text { Smoking history: smoking at time of } \\
\text { study }(\%) \\
\text { number of cigs/day }{ }^{\dagger} \\
\text { years smoked }{ }^{\dagger}\end{array}$ & $\begin{array}{l}38 \\
20 \pm 12 \\
21 \pm 10\end{array}$ & $\begin{array}{l}59 \\
21 \pm 8 \\
13 \pm 4\end{array}$ & $\begin{array}{l}54 \\
21 \pm 10 \\
18 \pm 8\end{array}$ & $\begin{array}{l}69 \\
24 \pm 11 \\
17 \pm 7\end{array}$ & $\begin{array}{l}p<0.05 \\
\text { NS } \\
p<0.05\end{array}$ \\
\hline
\end{tabular}

Results expressed as mean $\pm \mathrm{SD}$, or range (in parentheses).

*In patients with measurable C-peptide concentration only.

+Smokers only.

underrepresented in type 1 diabetics in this or previous studies. HLA A1 and B8 were significantly $(\mathrm{p}<0.01$ and $<0.001)$ overrepresented (relative risks $=2.18$ and 3.34$)$ and $B 7$ significantly $(p<0.001)$ underrepresented (relative risk $=0.40$ ) in all diabetics (groups A-D) in comparison with controls. The combination of A1 and B8 was more frequently $(\mathrm{p}<0.001)$ found in all diabetics (groups A-D) than in controls (relative risk $=3 \cdot 51$ ).

The frequency of HLA B7 was greater $(p<0 \cdot 05)$ in nonretinopaths (group $A$ ) than in all retinopaths (groups B-D) and greater $(p<0.05)$ than in diabetics with proliferative retinopathy (groups $C$ and D). None of the 27 patients in group D exhibited HLA B7. The frequencies of inferred homozygosity of HLA B7 and B8 were 3\% and $15 \%$ in diabetic nonretinopaths, $0 \%$ and $15 \%$ in diabetic retinopaths, and $2 \%$ and $1 \%$ in nondiabetic controls.

\section{Hba, AND POSTPRANDIAL PLASMA GLUCOSE CONCENTRATIONS}

Table 3 shows the mean $\mathrm{HbA}_{1}$ and postprandial plasma glucose values of diabetics in groups A-D. There was no significant difference between plasma glucose values of patients in groups B-D whose overall mean value $(16 \cdot 4 \pm 8 \cdot 8 \mathrm{mmol} / \mathrm{l})$ was significantly higher $(p<0.01)$ than that of patients in group A $(12.6 \pm 5 \cdot 8 \mathrm{mmol} / \mathrm{l})$. Similarly, the mean $\mathrm{HbA}_{1}$ value of patients in groups B-D $(13 \cdot 8 \pm 2 \cdot 4 \%)$ was significantly higher $(p<0 \cdot 001)$ than that $(12 \cdot 1 \pm 1 \cdot 8 \%)$ of patients in group $\mathrm{A}$. There was a significant correlation between plasma glucose and $\mathrm{HbA}_{1}$ when retinopaths and nonretinopaths were considered together $(\tau=0.48, p<0.001)$ or separately $(\tau=0.46$, $\mathrm{p}<0.001 ; \quad \tau=0.22, \quad \mathrm{p}<0.01)$. The relationship between plasma glucose and $\mathrm{HbA}_{1}$ was similar in diabetics with and without a raised serum creatinine concentration. There was no significant relationship between $\mathrm{HbA}_{1}$ or plasma glucose and any HLA antigen when considering retinopaths or nonretinopaths. There was no significant relationship between visual acuity and $\mathrm{HbA}_{1}$ or plasma glucose concentration.

Current smokers had a higher mean $\mathrm{HbA}_{1}$ level than nonsmokers $(13.2$ versus $12.4 \% ; p<0.05)$, but this is largely accounted for by the higher proportion of smokers among retinopaths. The mean $\mathrm{HbA}_{1}$ of smokers within each of the groups A-D, while significantly higher than that of nonsmokers, is not significantly so in any group.

\section{INSULIN ANTIBODY BINDING}

The mean level of insulin antibody binding was not found to differ significantly among patients of groups A-D (Table 3). However, insulin antibody binding correlated significantly with age at study $(\tau=0 \cdot 18$, $\mathrm{p}<0.001)$ and duration of diabetes $(\tau=0 \cdot 16, \mathrm{p}<0 \cdot 01)$. Mean insulin antibody binding in patients taking once daily insulin $(25 \cdot 4 \pm 16.8 \%)$ was higher $(p<0 \cdot 001)$ than in those taking twice daily insulin $(16 \cdot 7 \pm 14 \%)$, while patients taking conventional beef insulin had higher $(p<0.001)$ insulin antibody binding $(23 \cdot 8 \pm 15.9 \%)$ than those taking highly purified pork insulin $(15 \cdot 6 \pm 15 \cdot 2 \%)$. There was no significant relationship between insulin antibody binding and daily insulin dose or plasma C-peptide concentration. Wilcoxon rank sum tests show mean insulin antibody binding to be lower $(p<0.01)$ in HLA B8 positive diabetics $(18.2 \%)$ than in HLA B8 negative diabetics $(25.0 \%)$ and to be higher $(p<0.05)$ in HLA B15 
positive diabetics $(27 \cdot 1 \%)$ than in HLA B15 negative diabetics $(20 \cdot 4 \%)$. The association between $\mathrm{B} 15$ and high insulin antibody binding was independent of the association between B8 and low insulin antibody binding. Mean insulin antibody binding was not significantly different in B7 positive $(26.9 \%)$ and negative diabetics $(20 \cdot 8 \%)$.

\section{C-PEPTIDE}

None of the nonretinopaths studied had a plasma C-peptide concentration greater than $0 \cdot 29 \mathrm{nmol} / \mathrm{l}$. No significant difference was observed in the frequency with which a measurable $C$-peptide concentration was found in patients of groups A, B, C, and D (30. 47, 25 , and $13 \%$ ). Table 3 shows that the mean plasma C-peptide concentration was not significantly different within groups A-D.

\section{BLOOD PRESSURE}

There was no significant difference in the prevalence of systolic or diastolic hypertension ( $>155$ and $>85$ $\mathrm{mmHg}$ ) in patients of groups A-C (Table 3). However, the prevalences of systolic and diastolic hypertension in group D $(41$ and $56 \%)$ were significantly greater $(p<0 \cdot 001$ and $<0.001)$ than in groups A-C (10) and $12 \%)$.

\section{SMOKING}

Table 3 shows the proportions of patients in groups A-D who were smoking cigarettes at the time of study and provides details of daily number of cigarettes smoked and duration of smoking in past and present smokers. Although retinopaths (groups B-D) included more $(\mathrm{p}<0.01)$ smokers $(60 \%)$ than nonretinopaths $(38 \%)$, this difference was mainly accounted for by the high prevalence of smoking in group D $(69 \%)$, being significantly greater $(p<0 \cdot 05)$ than in the other 3 groups of diabetics $(44 \%)$. These differences were not accounted for by the age differences in patients in groups A-D. There was no significant difference between the prevalence of smoking in patients of groups B and C combined $(56 \%)$ and that of patients in group A or group D. The significantly longer smoking history in group $A$ is presumably due to the greater mean age of patients in this group.

\section{Discussion}

A relationship between diabetic microangiopathy and an HLA antigen (or antigens) of the A, B, and/or $C$ loci has been proposed by several authors, ${ }^{7-14}$ whose findings are, however, contradictory owing to the heterogeneity of populations under consideration, the small numbers of patients studied, together with the absence or lack of adequate control data. Barbosa et al. ${ }^{14}$ reported a comparison of HLA antigen frequencies in large numbers of type 1 diabetics (aged less than 40 years at diagnosis of diabetes) with and without proliferative retinopathy. The frequency of B7 was significantly lower in proliferative retinopaths (7\%) than in diabetics without proliferative retinopathy $(20 \%)$, and our own findings are remarkably consistent $(5 \%$ in proliferative retinopaths versus $17 \%$ in nonretinopaths.) None of our 27 patients with proliferative retinopathy and diabetic nephropathy (group D) were B7 positive. A similar underrepresentation of HLA B7 was noted in type 1 diabetic proliferative retinopaths by Standl $e t$ al. ${ }^{15}$ Nevertheless we must concede that the difference in frequency of $B 7$ between proliferative retinopaths and nonretinopaths is modest, that it has not been noted in other studies, and that the aetiology of the putative protective influence of $\mathrm{B} 7$ remains obscure. We could not demonstrate a significant relationship between $\mathrm{B} 7$ and insulin antibody binding, although we have confirmed the association between high insulin antibody binding and the B15 positive, B8 negative genotype. ${ }^{16-18}$ Retinopaths and nonretinopaths had similar insulin antibody binding by serum in accordance with some ${ }^{12}$ but not all ${ }^{19}$ previous studies. It remains to be seen whether HLA $\mathrm{D} / \mathrm{DR}$ typing will clarify the issue concerning a possible genetic predisposition to diabetic microangiopathy. Preliminary data ${ }^{2021}$ suggest there is an association between HLA DR4 and diabetic retinopathy. The weak association between retinopathy and absence of HLA B7 may be the consequence of a yet stronger relationship between retinopathy and DR4.

We have shown retinopaths to have significantly higher $\mathrm{HbA}_{1}$ and plasma postprandial glucose concentrations than nonretinopaths. Our findings are therefore in accordance with those of Schanzlin et al. ${ }^{22}$ and West et al. ${ }^{23}$ in type 1 and 2 diabetics respectively. These observations have little bearing on the controversial issue concerning the relationship between long-term diabetic control and the aetiology of diabetic microangiopathy. However, it is interesting to note that the glycaemic control of nonretinopaths is not particularly good, albeit better than that of the retinopaths.

Systolic hypertension has been shown ${ }^{24}$ to precede the development of exudative retinopathy in middleaged diabetic Pima Indians (type 2 diabetics). In the present study neither systolic nor diastolic hypertension was commonly found in type 1 diabetics, most of whom were aged less than 50 years, unless accompanied by diabetic nephropathy. In particular. the prevalence of hypertension was no higher in retinopaths without accompanying nephropathy than in nonretinopaths. It therefore seems likely that 
hypertension is not a major aetiological factor in the development of severe diabetic retinopathy in type 1 diabetics. We have shown a strong relationship between hypertension and the association of proliferative retinopathy with diabetic nephropathy. While it seems probable that diabetic nephropathy was responsible for the development of hypertension in most cases, we cannot discount the possibility that hypertension was causally related to the development of nephropathy, or even retinopathy, in those patients with underlying diabetic nephropathy.

The present study confirms smoking to be more prevalent among retinopaths than nonretinopaths and is thus in accordance with the findings of Paetku et al. ${ }^{25}$ However, this difference appears to be due to the remarkably high prevalence of smoking in proliferative retinopaths who have diabetic nephropathy. This finding is in agreement with the observations of Christiansen, ${ }^{26}$ who reported heavy smoking to be a characteristic of diabetic nephropaths.

The present study suggests that the risk of development of diabetic microangiopathy is related not only to HLA associated genetic factors but also to cigarette smoking.

The authors gratefully acknowledge the skilled technical assistance provided by Judith Matthews. Margaret Sinclair. Dr A White. and C. Darg. We are also indebted to Miss L. Veitch for her invaluable secretarial assistance. The authors also gratefully acknowledge financial support provided by the British Diabetic Association. A.B.K. was further supported by a grant from Nordisk Insulin Laboratories.

\section{References}

1 Fraser DM. Smith AF, Grav RS. et al. Glvcosvlated haemoglohin concentrations in newly diagnosed diabetics before and during treatment. Br Med J 1979: i: 979-81.

2 Kvnoch PAM. Lehmann H. Rapid estimation (21/2 hours) of glycosvlated haemoglobin for routine purposes. lancet 1977: ii: $16-7$.

3 Svendsen PAA. Christiansen JS. Soegaard U. Welinder BS. Nerup J. Rapid changes in chromatographically determined haemoglobin $\mathbf{A}_{\mathrm{c}} \mathrm{c}$ induced by short-term changes in glucose concentration. Diahetologia 1980: 19: 130-6.

4 Morley G. Dawson A. Marks J. Manual and autoanalyser methods for measuring blood glucose using guaiacurn and glucose oxidase. Proc Assoc Clin Biochem 1968: 5: 42-5.

5 Kurtz AB. Matthews JA. Mustaffa BE. Daggett DR. Nabarro JDN. Reduction of antibodies to insulin. proinsulin and contaminating hormones after changing from conventional beef to purified pork insulin. Diabetologia 1980(): 18: 147-50.

6 Heding LG. Radioimmunological determination of human (peptide in serum. Diahetologia 1978: 11: 541-8.
7 Barhosa J. Noreen H. Goet\% F. Simmons R, de l.civa A. Najarian J. Yunis E. Histocompatibility (HI.A) antigens and diabetic microangiopathv. Tissue Antigens 1976: 7: 282-7.

8 Becker B. Shin DH. Burgess D. Kilo (C. Miller WV. Histocompatibility antigens and diabetic retinopathy. Diahetes 1977 : 26: $997-9$.

9 Larkins RG. Martin FIR. Tait DB. HI.A patterns and diabetic retinopathv. Br Med J 1978: i: 1111.

10 Moller E. Perrson B. Sterky G. HI.A phenotypes and diahetic retinopathv. Diahetologia 1978: 14: 155-8.

1 I Mann JI. Winearb B. Thorogood M. Bottazoo GF. Baum JD. Autoimmunity in juvenile diabetics and their families. Br Med J 1978: ii: 1436 .

12 Deckert T. Fgeherg J. Frimodt-Moller C. Sandu F. Svejgatard A Basement membrane thickness. insulin antibodies and HI.A. antigens in long standing insulin dependent diabetics with and without severe retinopathy. Diahetologia 1979: 17: 91-6.

13 Cudworth AG. Bottazzo (iF. Doniach D. Genetic and immunological factors in type 1 diabetes. In: Irvine WJ. ed. Immunologv of Diahetes. Edinburgh: Teviot Scientific Publications. chapt. 3: 67-9.

If Barbosa J. Ramsay RC. Knobloch WH. Cantril MM. Noreen H. Yunis E. Histocompatibility antigen frequencies in diabetic retinopathv. Am J Ophthalmol 1981): 90: 1+8-53.

15 Standl F. Dexel T. L.ander T. et al. Association of HI.A antigens with severity of diahetic retinopathy in Southern Germany. Horm Metah Res Suppl 1981: 11: 81-6.

If Bertrams J. Jansen FK. (Gruncklec D). et al. HI.A antigens and immunoresponsiveness to insulin in insulin-dependent diabeter mellitus. Tissue Antigens 1976: 8: 13-9.

17 Irvine WJ. Di Mario U. Feek CM. et al. Insulin antihodies in relation to islet cell antibodies and HI.A antigens in insulindependent (tvpe 1) diabetes. J (lin I.ah Immunol 1978: 1: 111-4.

18 Schernthaner G. Ludwig H. Maur WR. Immunoglohulin $\mathrm{G}$-insulin antibodies and immune region associated autoantigens in insulin-dependent diabetes mellitus. J (T.in Eindocrinol Metah 1979; 48: 4(1)3-7.

19 Anderson OO. Anti-insulin antihodies and late diahetic complications. Acta Endocrinol (Khh) 1975: 83: 329-41)

2) Bertrams J. Dewald G. Spitznas M. Rittner Ch. HI.A-A. B.C. DR. Bf and $C 2$ alleles in insulin-dependent diabetes mellitus with proliferative retinopathy. Immunohiology (Stuttgart) 1980): 158: $113-8$.

21 Dornan TI. Ting A. McPherson K. Plowright (. Mann JI. Turner RC. Poor diabetic control and genetic ivpe (HI.A-DRt) are risk factors for retinopathy in insulin dependent diabetes. Diahetologia 1981: 21 : 265 .

22 Schanzlin DJ. Jay WM. Fritz KJ. Tripathi RC. Gonen B Hemoglohin $A_{1}$ and diabetic retinopathy. Am $J$ Ophthalmol 1978: 88: 10)32-8.

23 West KM. Frdreich 1.J. Stober JA. A detailed study of risk factors for retinopathy and nephropathy in diabetes. Diahetes 198(): 29: 501-8.

24 Knowler WC. Bennett PH. Ballintine EJ. Increased incidence of retinopathy in diabetics with elevated blood pressure. A six vear follow-up in Pima Indians. N Engl J Med 1980): 302: 645-50.

25 Paetku ME. Boyd TAS. Winship B. Grace M. Cigarette smoking and diabetic retinopathy. Diahetes 1977: 26: 46-9.

2h Christiansen JS. Cigarette smoking and prevalence of microangiopathy in juvenile-onset insulin-dependent diabetes mellitus Diahetes Care 1978: 1: 146-9. 